\title{
APLICAÇÃO DA TEORIA DOS DOIS FATORES: UM ESTUDO DE CASO EM UMA LOJA DE CALÇADOS NO MUNICÍPIO DE SALGUEIRO
}

\author{
Maria Tamires Lopes de Barros (UNIVERSIDADE DE PERNAMBUCO) \\ Thamyreslopes2012@ hotmail.com \\ Eryka Fernanda Miranda Sobral (UNIVERSIDADE DE PERNAMBUCO) \\ Eryka.sobral@upe.br \\ Fagner José Coutinho de Melo (UNIVERSIDADE DE PERNAMBUCO) \\ Fagner.melo@upe.br
}

\section{Resumo}

A motivação leva as pessoas a fazerem uma determinada tarefa, é ela que impulsiona o ser humano, a buscar alcançar aquilo que almeja. Compreender a motivação humana talvez seja um pouco difícil para alguns gestores. Apesar de existir várias teorias e hipóteses, muitos deles não sabem adotar suas práticas e levar para dentro da sua organização. Desta maneira a presente pesquisa teve por objetivo avaliar os fatores higiênicos e motivacionais no ambiente de trabalho, segundo a Teoria de Herzberg, através de um estudo de caso com a aplicação de um questionário em uma empresa de calçados na cidade de Salgueiro, avaliando assim, o grau de satisfação de seus trabalhadores com relação às condições de trabalho. A amostra selecionada foi de 10 funcionários de empresa estudo de caso. Como resultado, foi verificado que os fatores que geram maior satisfação nos funcionários da empresa de calçados, estão relacionados a responsabilidade dentro da organização e a competência do seu supervisor. Por outro lado, os fatores que geram insatisfação segundo os funcionários, estão relacionados à segurança, status, reconhecimento de desempenho e progresso profissional.

Palavras-Chaves: Teoria da motivação; Setor de serviço, Estratégia organizacional; Fatores higiênicos; Fatores motivacionais.

\section{Introdução}

O mundo empresarial exige cada vez mais que os trabalhadores estejam motivados no desempenho de suas atividades, pois a motivação é um impulso para que as pessoas consigam atingir seus objetivos, e é vista como o principal combustível para a produtividade de uma empresa (CALÁBRIA et al., 2018). A motivação gera estímulos que desenvolve nas pessoas a vontade de agir, esta força tem sua origem a partir de uma necessidade (ALBURQUERQUE et al., 2019).

Diante da competitividade dentro do mercado de trabalho, é necessário que os profissionais atendam as demandas de trabalho e paralelo a isso, estejam motivados para continuar superando os desafios emergentes das corporações. As empresas estão investindo na motivação de seus colaboradores de uma forma mais intensiva, com o intuito de ter um 
colaborador mais preparado e satisfeito, a fim de trazer resultados para o seu ambiente de trabalho (CALÁBRIA et al., 2018).

A qualidade de vida (QVT) é um conjunto de ações que implantam melhorias no ambiente de trabalho, com inovações na gerência e na tecnologia que prezam o bem-estar do empregado. Na prática a qualidade de vida oferece ao colaborador atenção, preocupação com o seu bemestar, melhorias, um bom ambiente de trabalho, e ainda favorece o desenvolvimento profissional do colaborador (CAMPOS et al., 2019).

Desse modo, a mesma emerge como uma preocupação com a sua saúde, bem-estar e motivação dos trabalhadores. Um funcionário motivado, vai buscar oportunidades de crescimento, o que por sua vez, o levará a atingir metas propostas pela empresa. Em contrapartida, a empresa precisa estar devidamente organizada para apresentar de modo claro como o profissional poderá ascender na estrutura organizacional (CAMPOS et al.,2019)

Dentre os diversos tipos de empresas, particularmente, nas pequenas e médias, suas principais dificuldades estão relacionadas a retenção de talentos, uma vez que as empresa muitas vezes não conseguem definir as exigências de cada cargo (MAHL et al., 2018).

Em pleno século XXI, as empresas precisam de colaboradores talentosos e qualificados para construir um negócio bem-sucedido. Como essas pessoas são cada vez mais procuradas no mercado, ter uma estrutura de pagamento atraente é muitas vezes a chave para atrair os melhores candidatos e reter os talentos. Um sistema de remuneração justo e uma boa política de cargos e salários são maneiras eficazes de motivar e manter os funcionários na empresa, porém em meio a tantos fatores como uma má remuneração, o não reconhecimento do funcionário, a falta de um plano de carreira, a falta de motivação do gerente para com o funcionário, acarreta na desmotivação do mesmo, baixo rendimento, e emocional abalado (MAHL et al., 2018).

A empresa estudada foi uma loja de calçados que está no mercado há 43 anos, localizada nos estados de Pernambuco, Ceará, Rio Grande do Norte, Paraíba e Maranhão. Tendo uma franquia localizada no Shopping do município de Salgueiro-PE. Esta empresa foi escolhida se destacar como referência na cidade de Salgueiro, e também é muito conhecida pela sua variedade de calçados, e por ter um bom atendimento diferenciado das demais lojas do mesmo setor. Este é um empreendimento que traz muito capital para a região. Esse tipo de mercado foi escolhido porque é uma das indústrias mais tradicionais no Brasil, e no município de Salgueiro. 
Desta maneira, este estudo teve como objetivo avaliar os fatores higiênicos e motivacionais no ambiente de trabalho, segundo a Teoria de Herzberg, através da aplicação de um questionário em uma loja de calçados no município de Salgueiro. A empresa possui 14 funcionários, porém 4 funcionários se abstiveram a responder. Portanto a amostra selecionada foi de 10 funcionários de empresa estudo de caso.

Esta pesquisa foi estruturada em quatro seções. Na primeira parte da seção encontra-se a introdução. Na segunda foi apresentado os conceitos que nortearam este trabalho, na terceira foi descrita a metodologia da pesquisa e por fim os resultados da pesquisa.

\section{Revisão da literatura}

Nessa seção, estão apresentados os principais tópicos que nortearam este trabalho, como: a teoria da motivação e teoria dos dois fatores.

\subsection{Teoria da Motivação}

Robbins (2005) divide a teoria da motivação em teoria antiga sobre motivação composta pela teoria da hierarquia de necessidades, teoria $\mathrm{X}$ e $\mathrm{Y}$ e a teoria dos dois fatores e as teorias contemporâneas sobre a motivação composta pela teoria ERG, teoria das necessidades de McClelland, teoria da avaliação cognitiva, teoria da fixação de objetivos, teoria do reforço, teoria do planejamento do trabalho, teoria da equidade, teoria da expectativa e a teoria da capacidade e oportunidade.

Existem várias teorias que abordam a teoria da motivação, onde é possível destacar a Teoria das necessidades criada por Maslow. Abraham Maslow (1908-1970), foi um psicólogo americano, que desenvolveu sua visão, sobre a motivação. $\mathrm{Na}$ sua teoria, as necessidades humanas estão organizadas por níveis de importância, sendo as mais básicas na base de sua pirâmide e as de realização pessoal no topo da mesma (CHIAVENATO, 2014). A Figura 1 descreve cada nível das necessidades elaboradas por Maslow. 


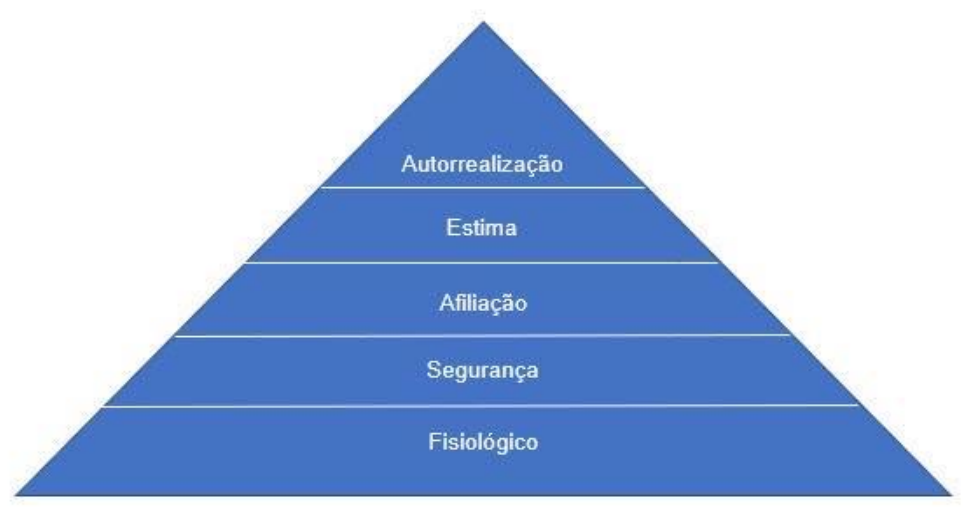

Fonte: Adaptado de Chiavenato (2014)

- Necessidades Fisiológicas: São as necessidades mais básicas, como alimentação, moradia, sono, sexo, vestimenta, etc.

- Necessidades de Segurança: estabilidade no emprego, proteção, etc.

- Necessidades Sociais: Correspondem as necessidades de interação, de amizade, de ser amado, de ter amizades, e ser aceito pelo outros.

- Necessidades de Estima: É como as pessoas querem ser vistas na sociedade, importantes, de grande influência, elas procuram possuir status, prestígio e poder.

- Necessidades de Auto Realização: É o nível mais alto de todas as necessidades, quando todas as outras são supridas.

\subsection{Teoria dos Dois Fatores}

Frederick Herzberg, psicólogo, visando estabelecer uma conexão com a teoria de Maslow, propôs a teoria dos dois fatores, que ficou conhecida como a Teoria da Higiene. O Autor estudou quais são os fatores que causam satisfação ou insatisfação nos trabalhadores, o que os motiva ou desmotiva (Albuquerque et al., 2019).

Para chegar a essas conclusões, segundo Robbins, Herzberg buscou responder à seguinte questão “O que as pessoas desejam do trabalho?”. Diante das respostas obtidas, segundo Herzberg apud Robbins (2005, p. 135):

“Os dados sugerem que o oposto da satisfação não é a insatisfação, como normalmente se acredita. A eliminação das características de insatisfação não o torna necessariamente satisfatório... O oposto de "Satisfação" é "Não - Satisfação" e o oposto de "Insatisfação" é "Não- Insatisfação". Portanto, os executivos que procuram eliminar os fatores que geram insatisfação podem conseguir paz, mas não necessariamente a motivação dos funcionários”. 
Diante dessa avaliação foi possível identificar que os fatores higiênicos eram os benefícios oferecidos pela empresa, eram os fatores que podem gerar uma insatisfação no empregado, como condições ambientais, relações interpessoais, status, remuneração e vida pessoal. Enquanto os fatores motivadores estavam relacionados ao cargo ocupado pelo empregado, como realização, reconhecimento, responsabilidade, desenvolvimento pessoal e possibilidade de crescimento (DAFT, 2007; ALBUQUERQUE et al., 2017). Ramos (1990) afirma que os fatores motivadores são de ordem mais pessoal, como realização, o reconhecimento. Enquanto os fatores higiênicos não estão relacionados ao trabalho em si, pois são sujeitos as ordens da empresa.

\section{Metodologia}

Esta pesquisa foi classificada quanto ao objetivo, quanto à abordagem e quanto ao método. Quanto ao objetivo esta pesquisa foi classificada como exploratória uma vez que existem poucos estudos a respeito do objeto de estudo, propiciando assim maiores informações sobre o tema. Quanto a abordagem esta pesquisa foi considerada como qualitativa uma vez que esta pesquisa busca trazer informações sob o tema explicado e quanto ao método foi considerada um survey pois, há a necessidade de interrogar diretamente pessoas das quais se deseja conhecer o comportamento (Gil, 2017).

Para atender ao objetivo do trabalho foi elaborado um questionário adaptado de Medeiros (2009). Esse instrumento de coleta tem como objetivo avaliar os Fatores Higiênicos e Motivacionais no Ambiente de Trabalho em empresa de calçado no município de Salgueiro. O questionário foi dividido em duas partes. A primeira parte visou estudar o perfil dos respondentes (Questões de 1 a 10). A segunda parte visou estudar os fatores motivacionais por meio das dimensões o trabalho em si, a realização, o reconhecimento, o progresso profissional, a responsabilidade, o desenvolvimento pessoal: e o enriquecimento do cargo e os Fatores higiênicos por meio das dimensões: as condições de trabalho, as políticas administrativas, o salário, o relacionamento interpessoal, a segurança, o status e a competência do supervisor.

A empresa estudada trata-se de uma loja de calçados no município de Salgueiro com mais de 10 anos de mercado. A empresa possui 14 funcionários. Os questionários foram aplicados a 10 funcionários desta empresa. O tipo de serviço prestado pelos funcionários da empresa de calçados é considerado de médio volume e média variedade. O serviço é proporcionado através de combinações de atividades do pessoal de linha de frente e da retaguarda, por isso, trata-se de uma loja de serviço. 


\section{Resultados}

Nesta seção foram apresentados os resultados desta pesquisa como o perfil dos respondentes, os fatores higiênicos e os fatores motivacionais.

\subsection{Perfil dos Respondentes}

Para analisar os fatores higiênicos e motivacionais em uma organização é de extrema importância conhecer o perfil dos funcionários, para poder gerir a produtividade dos funcionários em suas respectivas funções. A instituição estudada possui 14 funcionários, entretanto foi realizada a pesquisa com a amostra de 10 funcionários. A Tabela 1 apresenta as informações da amostra por: Sexo, Faixa Etária, Escolaridade e Tempo de Trabalho no Instituto.

TABELA 1 - Perfil dos entrevistados

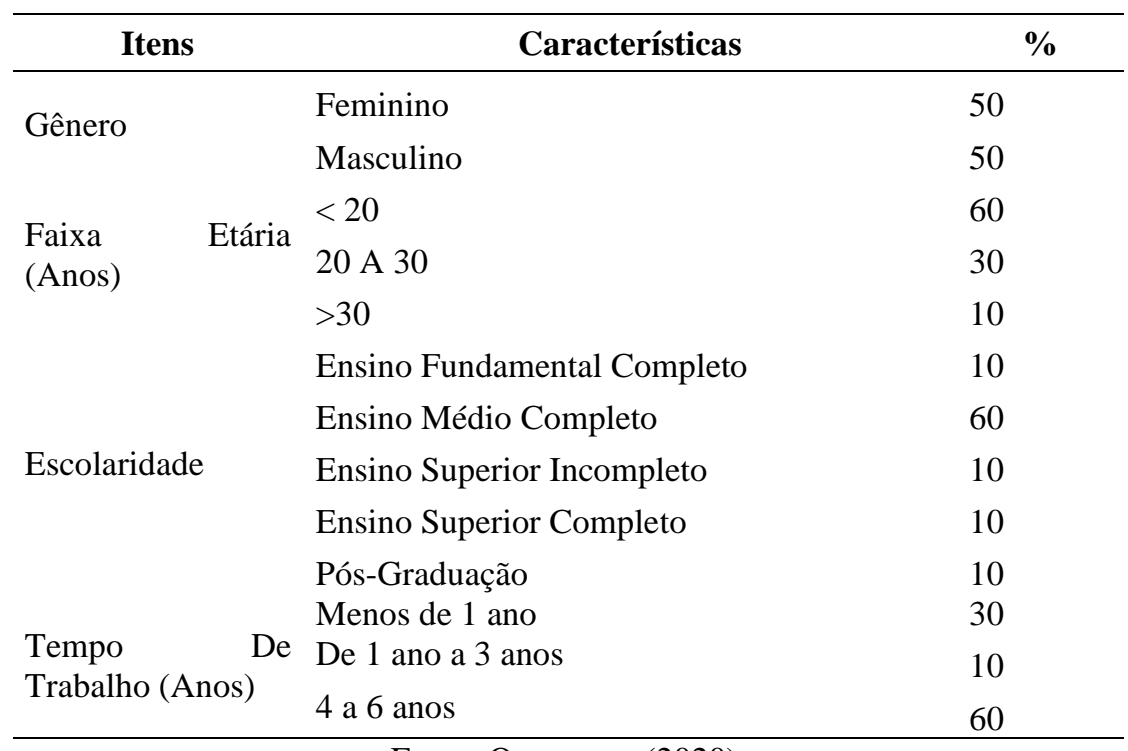

Fonte: Os autores (2020).

Com relação ao gênero, $50 \%$ dos entrevistados foram do sexo feminino e $50 \%$ dos entrevistados foram do sexo masculino. Em relação a faixa de idade, verificou-se que $60 \%$ dos entrevistados possuíam menos de 20 anos, 30\% possuíam na faixa de 20 a 30 anos e 10\% possuíam idade acima de 30 anos. Quanto a escolaridade, 60\% dos entrevistados possuíam o ensino médio completo, $10 \%$ dos entrevistados possuíam o ensino fundamental completo, $10 \%$ dos entrevistados possuíam o ensino superior incompleto e $10 \%$ dos entrevistados possuíam o ensino superior completo. Com relação ao tempo de trabalho, $60 \%$ do quadro de funcionários estava na empresa entre 4 e 6 anos, $30 \%$ do quadro de funcionários estava na empresa há menos de 1 ano e 10\% do quadro de funcionários estava na empresa entre 1 e 3 anos. 


\subsection{Fatores Motivacionais}

Nesta seção foram estudados os fatores motivacionais que são considerados fatores intrínsecos e estão relacionados ao conteúdo do cargo, às tarefas e às atividades relacionadas com o cargo em si (ALBURQUERQUE et al., 2019). Os fatores motivacionais estudados nessa seção foram o trabalho em si, realização, reconhecimento do desempenho, progresso profissional, maior responsabilidade, desenvolvimento pessoal e enriquecimento do cargo.

Esses fatores foram avaliados segundo a média dos respondentes. Para média menor que 4, os funcionários foram considerados muito insatisfeitos, para média entre 4 e 6 os funcionários foram considerados insatisfeitos, para média entre 6 e 7 os funcionários não foram considerados insatisfeitos e nem satisfeitos, para média entre 7 e 8 os funcionários foram considerados satisfeitos e para média acima de 8 os funcionários foram considerados muito satisfeitos. Na Tabela 2 foi apresentada as médias gerais para os seguintes fatores motivacionais da organização estudada.

TABELA 2- Média geral dos Fatores Motivacionais

\begin{tabular}{lcc}
\hline \multicolumn{1}{c}{ Fatores motivacionais } & Média Geral & Classificação do fator \\
\hline Trabalho & 7,85 & Satisfeitos \\
Realização & 7,60 & Satisfeitos \\
Reconhecimento do desempenho & 6,73 & Nem insatisfeitos e nem satisfeitos \\
Progresso profissional & 6 & Nem insatisfeitos e nem satisfeitos \\
Maior responsabilidade & 9,2 & Muitos satisfeitos \\
Desenvolvimento pessoal & 7,55 & Satisfeitos \\
Enriquecimento do cargo & 7,35 & Satisfeitos \\
\hline
\end{tabular}

Fonte: Os autores (2020).

Conforme foi apresentado na Tabela 2, foi identificado que os funcionários, estão relativamente satisfeitos com o trabalho, tendo a motivação como base para a produtividade. As questões 1 e 2, referente ao trabalho em si, os funcionários exercem sua função e estão realizados com isso, tiveram uma média de 7,85 mostrando que os funcionários da empresa de calçados estavam satisfeitos com o trabalho. De acordo com Albuquerque et al., (2019) e Albuquerque et al., (2017), a média dos funcionários estudados foram respectivamente 7,11 e 7,77 , onde mostra que o grau de satisfação também se compara aos do estudo em questão, todos estão satisfeitos.

O fator realização impacta muito na vida do funcionário, é o que mostra se ele está feliz no cargo em que ocupa e se isso o satisfaz, ela é uma fonte de autoestima e obteve média de 7,60, os funcionários estavam satisfeitos. Este fator trata do interesse pessoal em realizar novas atividades. Para este fator, a maioria dos funcionários confirmou que há um grande interesse em realizar novas tarefas. O mesmo acontece com amostra de Albuquerque et al., (2019) com 
uma média de 8,4. O fator ser reconhecido pelo seu desempenho, obteve uma média de 6,73. Este fator não gerou satisfação nem insatisfação no funcionário, o mesmo aconteceu com os resultados de Albuquerque et al., (2019) e Albuquerque et al., (2017), com as médias de 6,1 e 5,45 . Essas médias só ressaltaram que os funcionários não queriam ser vistos apenas como uma máquina de trabalhar, mas como um colaborador para a organização.

O fator progresso profissional, mais sintetizado como planos de carreira, obteve média 6,0, mostrando que os funcionários não estavam satisfeitos nem insatisfeitos. Para este fator foi desenvolvido um plano de ação. Albuquerque et al., (2019) também obteve o mesmo resultado com uma média de 6,2. O fator maior responsabilidade obteve a maior média 9,2. Este foi o fator mais bem avaliado, mostrando que os funcionários estavam muito satisfeitos. Este resultado vai de encontro com os obtidos em Albuquerque et al., (2019).

O fator desenvolvimento pessoal e enriquecimento do cargo, obtiveram respectivamente as médias 7,55 e 7,35, a partir dessas é possível notar que os funcionários estavam satisfeitos. Já no artigo de Albuquerque et al., (2019) não acontece o mesmo, com médias de 6,5 e 6,7 mostram que o interesse e esforço foi médio.

\subsection{Fatores Higiênicos}

Nesta seção foram estudados os fatores higiênicos que são considerados fatores extrínsecos e estão relacionados às condições físicas do ambiente de trabalho, salário, benefícios sociais, políticas da organização, clima organizacional, oportunidades de crescimento, etc. (ALBURQUERQUE et al., 2019). Os fatores higiênicos estudados nessa seção foram condições de trabalho, políticas administrativas, salários, relacionamento interpessoal, segurança, status e competência do supervisor.

Esses fatores foram avaliados segundo a média dos respondentes, para média menor que 4, os funcionários foram considerados muito insatisfeitos, para média entre 4 e 6 os funcionários foram considerados insatisfeitos, para média entre 6 e 7 os funcionários não foram considerados insatisfeitos e nem satisfeitos, para média entre 7 e 8 os funcionários foram considerados satisfeitos e para média acima de 8 os funcionários foram considerados muito satisfeitos. Na Tabela 3 foram apresentadas as médias gerais para os seguintes fatores higiênicos da organização estudada. 
TABELA 3-Média geral dos Fatores Higiênicos

\begin{tabular}{lcc}
\hline \multicolumn{1}{c}{ Fatores Higiênicos } & $\begin{array}{c}\text { Média } \\
\text { geral }\end{array}$ & Classificação do fator \\
\hline Condições de trabalho & 7,82 & Satisfeitos \\
Políticas administrativas & 7,9 & Satisfeitos \\
Salários & 7,8 & Satisfeitos \\
Relacionamento interpessoal & 7,36 & Satisfeitos \\
Segurança & 5,54 & Insatisfeitos \\
Status & 6,95 & Nem insatisfeitos e nem satisfeitos \\
Competência do supervisor & 8,75 & Satisfeitos \\
\hline & Fonte: Os autores (2020).
\end{tabular}

De acordo com os dados coletados o fator de condições no trabalho, está relacionado ao local apresenta uma boa higiene, localização e acesso físico, sendo que sua média foi 7,82. Significa que os funcionários estavam satisfeitos. Em Albuquerque et al., (2019) deixam a desejar com uma média de 6,1 só mostram o grau de insatisfação do empregado com a localização e o acesso físico.

A questão das políticas administrativas, obteve uma média geral no valor de 7,9 isso mostrou que a maioria dos funcionários ficaram satisfeitos com as políticas da empresa, em Albuquerque et al., (2019) a média 6,6 mostrou também uma satisfação dos funcionários. Outro fator analisado foi a base salarial, que incentiva muito o funcionário de uma maneira positiva com uma média de 7,8 os funcionários demonstram satisfação, na pesquisa de Albuquerque et al., (2019) com uma média de 5,8 os empregados demonstram nem satisfação e nem insatisfação.

O fator de relacionamento interpessoal da questão 33 a 35 obteve uma média de 7,36 mostrando que os funcionários estavam satisfeitos com o trabalho em grupo. Para Albuquerque et al., (2019) a média foi de 7,1 o que mostrou que eles estão satisfeitos. O fator segurança também foi analisado com uma média de 5,54 mostrando que a situação é precária e os funcionários se encontram insatisfeitos. A partir da baixa média devem-se criar planos de ação para melhorar a satisfação dos funcionários. Em Albuquerque et al., (2019) também traz uma média baixa com 6,3 mostrando também a insatisfação dos seus empregados.

O fator status mostrou que grande parte não tem seu esforço reconhecido pela chefia e não se sentem satisfeitos no cargo que ocupam com uma média de 6,95. Em Albuquerque et al., (2019) a média também foi baixa com 4,9. O último fator que fala da competência do superior, obteve a maior média de 8,75. Mostrando que os funcionários estavam satisfeitos com a gerência e que o mesmo motiva os funcionários, procurando também trazer melhorias para a organização. Em Albuquerque et al., (2019) a média apresentada foi de 7,3 mostrando que eles nem estava satisfeitos e nem insatisfeitos. 


\section{Conclusão}

Considerando que para motivar uma pessoa, várias questões são abordadas, a instituição estudada, mostrou que gera um grau mediano de satisfação e motivação em grande parte de seus funcionários, onde a mesma mostra que ela se preocupa com o bem-estar de seus funcionários, e que busca trazer sempre o melhor para eles.

Analisa-se que os resultados que geram maior satisfação em seus empregados estão relacionados à responsabilidade dentro da organização e também na competência do seu supervisor. Por outro lado, os fatores que obtiveram as menores médias segundo os funcionários, estão relacionados à segurança, status, reconhecimento de desempenho e progresso profissional.

Desta maneira, a empresa deve investir mais no progresso profissional, fazendo um plano de carreira, onde os funcionários podem ver como uma forma de crescimento dentro da organização, esta ação ocasionaria mais status para o funcionário, gerando um grau de autoestima. O plano de carreira por sua vez pode impactar positivamente no fator segurança uma vez que o funcionário teria uma "estabilidade" no seu ambiente de trabalho. Outra ação que pode ser realizada é o prêmio do funcionário do mês, para mostrar o reconhecimento profissional dos funcionários.

Buscando a melhoria através dessa análise, este estudo demonstrou relevância a organização em poder mudar e motivar seus funcionários, para que fatores como reconhecimento de desempenho e um plano de progresso profissional possam ser inseridos, afim de gerar maior satisfação no funcionário, onde o mesmo poderá crescer como profissional e agregar tanto valor para a organização, quanto para si mesmo.

\section{REFERÊNCIAS}

ALBUQUERQUE, L. A. C. S.; LUCENA, M. A.; SANTANNA, C. H. M.; GUIMARAES JUNIOR, D. S.; MELO, F. J. C. Teoria de Herzberg: Um Estudo de Caso em uma Escola Pública Municipal no Interior de Pernambuco. In: XXVI SIMPEP, Bauru- SP, 2019.

ALBUQUERQUE, A. P. G.; XAVIER, L. A.; MELO, F. J. C. Avaliação dos fatores higiênicos e motivacionais: um estudo de caso em uma empresa do setor de limpeza. In: V Simpósio de Engenharia de Produção - SIMEP, 2017, Recife-PE, 2017.

CAlÁBRIA, F.; MELO, F. J. C.; ALBUQUERQUE, A. P. G.; JERONIMO, T. B.; MEDEIROS, D. D.Changing the training paradigm for learning: A model of human capital development. Energy \&Environment, Vol. 29, pp. 1455-1481, 2018.

CAMPOS, E.V.; Carvalho, A.M.A.; Souza, A.S. Satisfação no Trabalho e Qualidade de Vida de Professores Universitários Brasileiros. Revisão Integrativa Multitemas, Vol. 24, n. 57, pp.57-77, 2019.

CHIAVENATO, I. Teoria Geral da Administração. 9. ed. São Paulo: Saraiva, 2014. 
DAFT, R. Administração. 6 ${ }^{\text {a }}$ ed. São Paulo: Thompson, 2007

FERREIRA, A. Teorias de motivação: uma análise da percepção das lideranças sobre suas preferências e possibilidade de implementaridade. IN: XIII SIMPEP, Bauru, SP, 2006.

GIL, A. C. Gestão de Pessoas - Enfoque nos Papéis Estratégicos.2. ed. São Paulo: Atlas, 2016.

MAHL, A. C.; SILVA, S. B. Estratégias Voltadas para Retenção de Talentos em Pequenas Empresas. Anuário Pesquisa e Extensão Unoesc São Miguel do Oeste, São Miguel do Oeste, p.1-16, 2018.

MEDEIROS, D. D. A fuzzy model to evaluate the motivation to quality programs. International Journal of Computers, Vol. 3, pp. 230-237, 2009.

RAMOS, J. P. Motivação no trabalho: abordagens teóricas. Revista de Psicologia, vol.1, n.2, 1990.

ROBBINS, S. P. Comportamento organizacional. 11. ed. São Paulo: Pearson Prentice Hall, 2005.

VIEIRA, C.B.; Boas; A.A.V.; Andrade, R.O.B.; Oliveira, E.R. Motivação na Administração Pública: considerações teóricas sobre a aplicabilidade dos pressupostos das teorias motivacionais na esfera pública. Revista ADMpg gestão estratégica. v. 4, n. 1, pp. 1-18, 2011. 